\title{
EDITORIAL
}

\section{A INOVAÇÃO EM ENFERMAGEM}

\author{
INNOVATION IN NURSING
}

\section{LA INNOVACIÓN EN ENFERMERÍA}

\author{
Alacoque LorenZini ERDMANN \\ Professora Titular da Universidade Federal de Santa Catarina. \\ FloRIANÓPOLIS (SC), BRASIL.
}

\begin{abstract}
avanço da Enfermagem como profissão social e como ciência, tecnologia e inovação vêm sendo resultado de um esforço coletivo liderado pelos pesquisadores da área tendo como alvo o alcance de um impacto significativo na qualidade do cuidado e melhor saúde da população.
\end{abstract}

Assim, as políticas indutoras de inovação na Enfermagem buscam propiciar um ambiente favorável a aplicação das novas tecnologias na prática profissional visando gerar mais saúde e qualidade de vida reconhecendo a saúde e a vida humana como um bem social, acompanhada da importância do desenvolvimento sócio-econômico do país.

A Enfermagem como disciplina, campo de conhecimento científico e tecnológico, e como profissão social vem estabelecendo medidas de incentivo à inovação e à pesquisa científica e tecnológica especialmente no âmbito das Universidades ou nos Programas de Pós-Graduação stricto senso e respectivos grupos de pesquisa mediante atividades de inovação, empreendedorismo, incubação, propriedade intelectual, transferência de tecnologia e registro de patente.

Essa evolução vem sinalizando a importância e necessidade de acompanhar o domínio do avanço da ciência, do processo de transferência do conhecimento, produção de tecnologias, implementação da tecnologia na prática e avaliação do impacto no cuidado e na saúde da população.

Para que estes avanços se concretizem é importante o domínio da gestão da propriedade intelectual mediante o estimulo e proteção da mesma, balizados de 
acordo com os preceitos da Lei de Inovação, aspecto legal que cada país possui, e esta Lei no caso, é específica do Brasil. É válido ressaltar que esta gestão empreende o trabalho da comunidade acadêmica, a difusão da valorização da propriedade intelectual, a promoção da transferência de tecnologia, a difusão da cultura da inovação, o estimulo e amparo a incubação de empresas resultantes de iniciativas da comunidade acadêmica e/ou de seus egressos, e, o estimulo ao empreendedorismo no ambiente acadêmico e comunidade externa.

O registro de patentes na área de enfermagem é emergente e de certo modo reflete o avanço tecnológico do país na área de saúde (1) o que requer políticas de promoção, estímulo e apoio a pesquisas com potencial para gerar inovações e domínio do processo de registro de patente.

Para tal, no Brasil, os participantes do IV Encontro Nacional de Pós-Graduação na Área de Ciências da Saúde, 2010 elaboraram uma Proposição da Área da Enfermagem com vista a promoção da inovação em enfermagem pelos programas de pós-graduação da Área, assim constituída: 10) estimular a criação de ambientes de tecnologia e inovação para desenvolvimento de modelos de cuidado de Enfermagem e Saúde, com estratégias de sustentabilidade e empreendedorismo; $2^{\circ}$ ) investir na criação de indicadores de impacto econômico e social, de tecnologia e inovação em Enfermagem e Saúde; $3^{\circ}$ ) promover a criação de redes de desenvolvimento de inovação e tecnologia em Enfermagem e Saúde, para garantir um cuidado de enfermagem seguro e de excelência; $4^{\circ}$ ) propor, às agências de fomento, de Editais temáticos de tecnologia e inovação em cuidados, gerência e educação em Enfermagem e Saúde, em consonância com as políticas do Sistema Único de Saúde; 5) propor a inclusão das tecnologias de cuidado de Enfermagem na Agenda de Prioridades em Pesquisa do Ministério da Saúde; $6^{\circ}$ incrementar a política de expansão e articulação dos programas de Pós-Graduação da Área de Enfermagem, como estratégia de qualificação dos profissionais de serviço com implantação de tecnologias de cuidado baseado em evidências (2).

Além desta proposição, também contamos com políticas do Comitê Assessor da Enfermagem no CNPq / CA-EF, para o desenvolvimento científico, tecnológico e de inovação na Área da Enfermagem, e, com políticas da Área de Enfermagem na Capes/MEC no perfil de formação dos pós-graduandos: mestres acadêmicos e profissionais e doutores em enfermagem. Estas políticas imprimem um caráter pedagógico com domínios para a criação de novas práticas: técnicas, processos, protocolos, modelos, produtos com registro de propriedade intelectual e patentes, visando distinção científica e tecnológica e inserção social, para a consolidação e fortalecimento da sua identidade pela contínua qualificação da investigação científica da Área.

Assim, reconhecemos que a inovação em enfermagem é hoje nosso maior desafio. Esta depende da produção de tecnologias avançadas de cuidados de 
enfermagem, do avanço da ciência da enfermagem e de nova pedagogia do ensinar-aprender. A soma de esforços, a determinação para alcançar metas, a implementação de novas estratégias para avanços nas descobertas, o estímulo ao potencial criativo na construção de conhecimentos avançados e tecnologias de alto impacto na sociedade é uma prática social desafiadora.

A prática do cuidado de enfermagem é um bem social da humanidade, muito além de um trabalho de mercado e é a maior riqueza que podemos gerar. Faremos diferença se incrementarmos a ciência, a tecnologia e a inovação da Enfermagem em todos os cenários e contextos sociais, produzindo conhecimentos científicos e tecnologias relevantes de Cuidado de Enfermagem, com profissionais altamente qualificados e reconhecimento do trabalho de cuidar do ser humano, seu acesso, consumo e impacto no gerar mais saúde.

\section{REFERÊNCIAS}

1. Koerich MHAL, Vieira RHG, Silva DE, Erdmann AL, Meirelles BHS. Produção tecnológica brasileira na área de enfermagem: avanços e desafios. Rev Gaucha Enferm. 2011; 32(4): 736-43.

2. Relatório da Área de Enfermagem do $4^{\circ}$ Encontro Nacional de Pós-Graduação na Área de Ciências da Saúde: como promover a inovação em saúde na pósgraduação? [Internet]. Bento Gonçalves, Brasil Porto Alegre: UFCSPA; 2010 nov 2-5 [citado 15 out 2011]. Disponível em: http://sistema.ufcspa.edu.br 